\title{
A Review on Controlling Techniques for Permanent Magnet Synchronous Motor (PMSM) and Current State of the Art in the Research Area
}

\author{
Parvathy Thampi M. S. \\ Research Scholar \\ Visvesvaraya Technological University, Belagavi, \\ Karnataka, India
}

\author{
Chitra Kiran N., PhD \\ Professor and HOD, Department of ECE, Alliance \\ College of Engineering and Design Alliance \\ University, Bengaluru, Karnataka, India
}

\begin{abstract}
The significance of Permanent Magnet Synchronous Motors (PMSM) is that it offers high performance and efficiency for motor drives. The controlling of the high-performance motor is characterized by smooth operation of the motor over entire speed range, control ability of torque even at zero speed, fast acceleration, and deceleration. The optimization of the speedcontrol performance under different constraints and uncertainties is the biggest concern in PMSM. In that sense, various speedcontrol mechanisms were presented towards identifying the better way to control PMSM drive having high-speed features and desired torque response. However, it is necessary to have a suitable control mechanism where the better adjustment of performance can be achieved for a different operating condition. However, it is quite hard to distinguish the system characteristics and dynamic control parameters during real-time operation due to complexity in PMSM system. This paper intends to present the survey of controlling strategies in PMSM and current research trends in PMSM. Along with the research gap, a futuristic line of research is presented.
\end{abstract}

\section{Keywords}

Permanent Magnet Synchronous Motors (PMSM), Performance, Speed, Control, Torque.

\section{INTRODUCTION}

The PMSM is high-performance electromechanical motion devices mainly overrides the conventional dc servo motors and induction machines because of its significant performance offering abilities [1]. The PMSM in terms of performance must have a speedy transient response with improvement in most of the applications. The high performance of PMSM control is characterized by uninterrupted operation of the motor over entire speed range, control ability of torque even at zero speed, fast acceleration and deceleration [2]. The optimization of the speedcontrol performance under different constraints and uncertainties is the biggest concern in PMSM. In that sense, various speedcontrol mechanisms were presented towards identify the better way to control PMSM drive control having high-speed features and desired torque response [3].

A PMSM is a synchronous motor which utilizes the permanent magnets than windings in the rotor, and it produces a fixed magnetic field. The PMSM can be considered as the cross among the AC induction motor (ACIM) and a brushless DC motor (BLDC) [4]. The PMSM exhibits similar kind of rotor construction like BLDC motors that contains permanent magnets. However, the stator construction of PMSM is resembled of ACIM in which the windings were constructed to generate a sinusoidal flux density machines air gap. Hence, the PMSM perform well best when driven by sinusoidal waveforms.
The PMSM are of two types which dependent on the mounting of permanent magnets, i.e., surface mounted and permanent interior magnets (IPC). The IPM is highly used PMSM which offers high performance and efficiency. Hence due to high performance and cost ratio of PMSM is widely used in variable speed applications [5].

This paper gives a survey on current research trend in PMSM controlling techniques. The organization of the paper is performed as: background of PMSM working operation and its applications (in section II), Controlling methods for PMSM control (in Section III), Review of existing controlling techniques (in Section IV), Research Gap (in Section V), current state of art in PMSM control (in Section VI) and Conclusion (in Section VII).

\section{PERMANENT MAGNET SYNCHRONOUS MOTORS (PMSM)}

The PMSM is a type of synchronous motor where the permanent magnet is utilized as a rotor to generate field poles while no field winding is wound over the rotor. The PMSM has a similar kind of construction like a synchronous motor. The main difference among the PMSM and the synchronous motor is rotor where the PMSM does not have filed winding over PMSM rotor. The magnets were placed over the core of rotor and based on which Surface Mounted and Buried or interior PMSMs can be classified. The magnets placed over the rotor surface indicates the Surface Mounted PMSM and is shown in figure.1 [1-5].

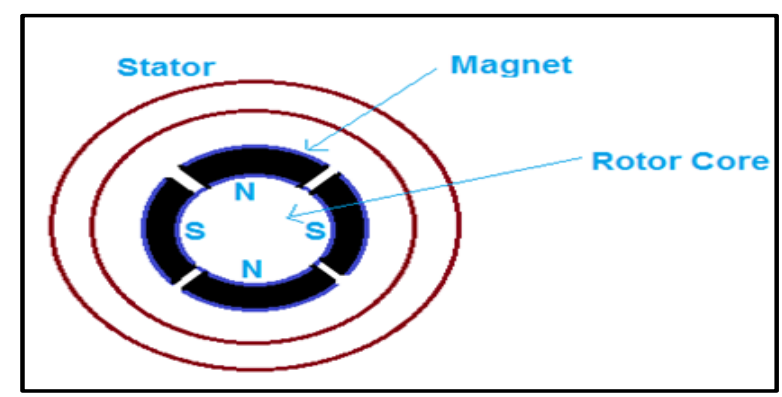

Fig 1: Surface Mounted PMSM

\subsection{Surface Mounted PMSM}

This is a robust PMSM and is helpful in high-speed applications. As the air gap and magnet permeability are same, this PMSM exhibits a uniform air gap, and hence no reluctance torque may exist. Hence, it is widely used in machine tool drives and robotics.

\subsection{Interior or Buried PMSM}

Here, the magnets were integrated into the rotor than placing over the surface. This is also applicable in high-speed 
applications, and it is robust too (shown in figure.2).

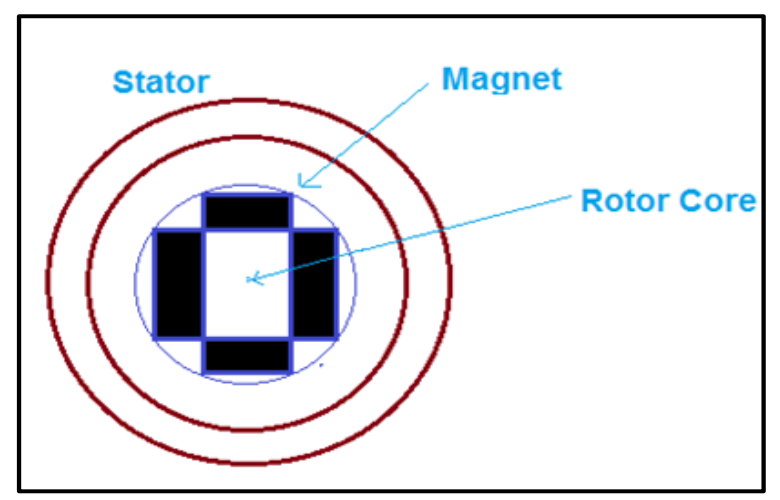

Fig 2: Interior PMSM

The PMSM works on the same principle of the synchronous motor. If the 3-phase stator winding is powered with 3-phase power supply, a rotating magnetic field may take place in the air gap. [1-2].

\subsection{Advantages of PMSM}

- This helps to remove heat generated in the stator.

- $\quad$ Enhances high torque per frame size.

- More reliable as it does not have brushes and commutator.

- Provides better efficiency.

- $\quad$ Provides better field orientation.

- Offers high-speed performance.

- Offers precise speed monitoring and regulation.

- Gives smooth torque.

- The PMSM can be used as a replacement for servo drives.

\subsection{Drawbacks of PMSM}

- It requires rotor position sensing.

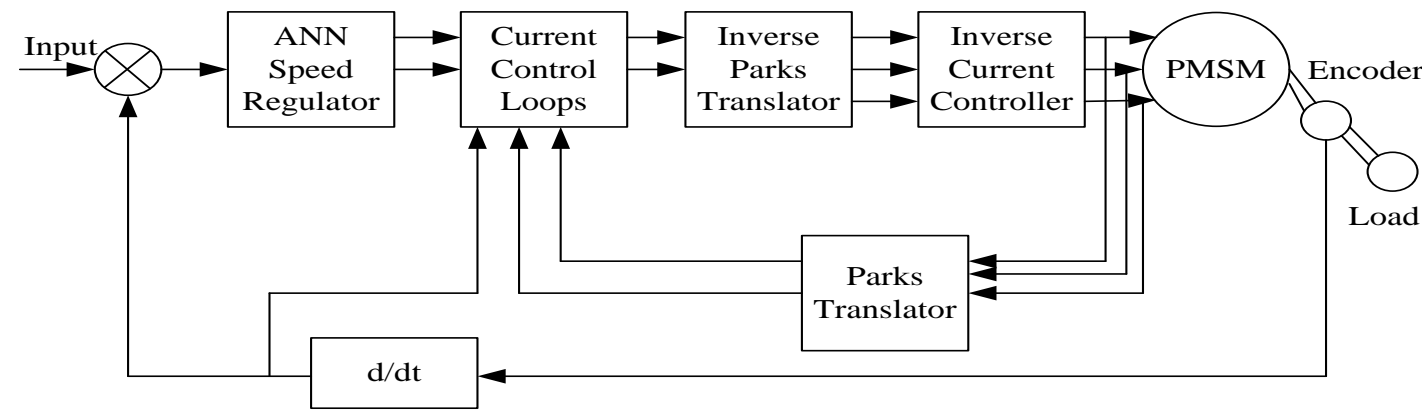

Fig.3: Block Representation of PMSM Speed Control using ANN Controller

The NN is the best replacement of traditional PI or PID controllers at it facilitates to compare the desired torque and speed to generate the error signal. The NN compensate the error and estimates motor torque, flux or flux angle at any operation. The application of two types of Artificial-intelligence based estimators like artificial neural network (ANN) or a fuzzy-neural network is discussed here. It is possible to train a supervised multi-layer feed forward ANN with back-propagation training for the estimation of the rotor position and the rotor angle. By using the backpropagation algorithm, the square of the error
- It needs a position sensor or sensor less technique to have a motor operation.

- It is very difficult to start the motor with the sensor less mechanism.

\section{CONTROLLING METHODS FOR PMSM}

The PMSM exhibit various kinds of control technique to adjust the performances of PMSM at different operating conditions. However, differentiating the performance characteristics of PMSM in real time implementation as it leads to the complexity issue in PMSM. Hence, many of the control mechanisms were introduced to enhance PMSM performance under different system uncertainties and disturbance factors. The control techniques involve adaptive control, sliding mode control, predictive control, fuzzy control, etc. These techniques were highlighted as below.

\subsection{Field Oriented Control}

This technique is utilized to decouple the flux and torque by transforming both the stator/phase current quantities to flux generating current quantities from a stationary reference frame in rotating reference frame just like dc machine. This approach improves the responses of transient and steady state.

\subsection{Sensorless Control}

The PMSM requires position sensors at rotor shaft during operation at no damper winding. The identification of rotor position is necessary to develop an efficient PMSM with enhanced performance. The accurate estimation of rotor position impacts on the starting torque. The inaccurate rotor estimation may lead to a reduction in torque and motor may rotate in the wrong direction [6]. The rotor position can be measured by using resolver, optical encoder, potentiometer, etc. among which encoders are the generally used device.

\subsection{Neural Network (NN) Control}

The use of NN in controlling the speed of PMSM is challenging function in the control system area. The following figure.4indicates the block representation of PMSM speed control. between the required and actual ANN output is minimized. ANN contains an input layer, an output layer, and the hidden layers. However, the total hidden layers required to be used will not be known which can be known by trial and error method. The average number of hidden layers mainly used were one or two. Also, hidden nodes are also not known, and it also found by trial and error method.

\subsection{Fuzzy Logic Control}

Fuzzy Logic Controllers are more robust to system plant parameter changes than the classical integral derivative 
controller (PID) and have better noise rejection capabilities. The fuzzy adaptive strategies are closer to the experts, reflecting their knowledge and experience. As the modern smooth control strategies grow in complexity, the fuzzy controllers are very competitive in high-performance drive applications. Hence, system performance/complexity ratio is generally higher for adaptive fuzzy controllers [7]. In conventional P, PI and PID controllers, which cannot cope up with system's parameter variations because of the required fine-tuning is low. Also, the performance of such controllers is affected due to the changes in physical parameters like temperature, noise, saturation, etc.

Many control systems use adaptive controllers for PMSM drive applications, which can track only linear systems. Hence, the fuzzy logic-based controller may be used to achieve an effective accurate and faster solutions and to handle complex non-linear characteristics. Fig. 5 gives the fuzzy control system consists of fuzzification, a rule database, rules inference and Defuzzification [8]. A simple structure Fuzzy Logic Controller (FLC) is utilized to regulate the motor speed. Several fuzzy control applications including the physical systems, require a real-time operation to interface high-speed constraints [6, 7]. Higher density programmable logic devices, such as field programmable gate array (FPGA) can be used to integrate large amounts of fuzzy logic in a single integrated circuit (IC). A direct adaptive controller uses a fuzzy logic system (FLS) as a controller, and it incorporates linguistic fuzzy control rules directly into the controller [9].

\subsection{Hybrid control Method}

The limitations of other mechanisms can be eliminated by collaboratively using different methods together (Hybrid). The following, some of these hybrid control methods are discussed.

\subsection{Robust Recurrent fuzzy neural network (RFNNC)}

A fuzzy neural network (FNN) that combines the capability of ANNs in learning from processes and fuzzy reasoning in handling uncertain information. This system brings robustness against uncertainties and in the design process.

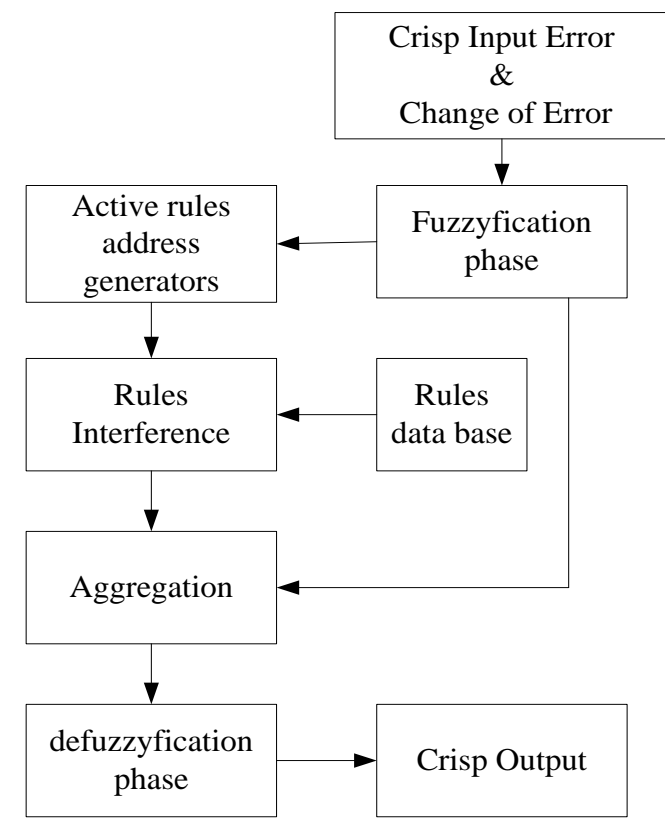

Fig.4: A Block Representation of Fuzzy Logic Controller

\subsection{Fuzzy Logic and Neural modelling}

Hybrid AI also plays a significant role in modelling such as in
[10] where experimental data approximation and "maps" of flux distribution, including non-sinusoidal flux distribution and saturation, are modelled. This method could also model friction and ripples as a function of speed and position.

\subsection{Neural Network Hybrid Controller and a \\ State Estimator}

The technique of combining control methods has been applied to mechanical vibration suppression. In [11], the research presents a combination of a neural network hybrid controller and a state estimator. This approach considerably reduces the vibration of the flexible mechanism in PMSM. The proposed controller is perceived to be stable for operating conditions with the aid of a differential evolution strategy and the Kalman filter method.

\subsection{Sliding Model Controller (SMC) and Neuro-Fuzzy Controller (NFC)}

A parallel connected SMC, and NFC system was introduced to control PMSM speed. The hybrid controller (HC) produced better performance compared to the SMC and the NFC in terms of lower control current chattering, good steady state speed response and very good transient and parameter variation speed response. Moreover, the $\mathrm{HC}$ shows robustness for different operating speeds, high accuracy, as well as insensitivity to changes in working conditions of the PMSM drive [12].

\section{REVIEW OF EXISTING RESOURCES}

This section explains the recently presented researches towards PMSM control with the aim of performance enhancement. In order to keep the search comprehensive, yet manageable, the IEEE journals and transactions have been primarily consulted (from 2015 to 2018). Towards evolutionary implementation of fuzzy logic based PID controller is presented in Choi et al. [1] where an evolutionary algorithm was adapted for fuzzy logic control in real time implementation and come up with feasibility and practicality in Texas Instruments. Similarly, the design of an adaptive PID controller for PMSM speed is found in Jung et al. [2]. The designed controller composed of decoupling, PID and supervisory control term. In this, the decoupling is meant for compensation of non-linear factors, PID is for automatic adjustment of control gains and supervisory for system stability. The author [2] has performed a performance analysis of adaptive PMSM with traditional PMSM controller where it was observed that the adaptive PMSM had achieved faster transient response and low steady-state error under parameter uncertainties.

In general, the sinusoidal-wave drive performs better in some aspects such as torque ripples, a starting performance, and a flux-weakening capability than the square-wave drive. The square-wave drive, however, has the advantage of higher efficiency at low-output-power conditions because of its relatively lower switching loss than the sinusoidal-wave drive. To selectively utilize the benefits of both driving modes, a seamless transition control between the two driving modes is proposed in Lee et al. [3]. With this [3] a dual-mode operation of the sensorless PMSM drive can be achieved without stopping the compressor. The dynamic performance of the proposed transition scheme is tested using simulations and verified by experiments. The outcomes of [3] give $20 \%$ increment in the efficiency of a refrigerator using the dual-mode operation in comparison with the sinusoidal-wave only drive.

The work of Lemmens et al. [4] gives an algorithm for optimal current trajectory control of (interior) PMSM drives, considering the motor/inverter current and voltage limitations. In contrast to common voltage feedback flux-weakening strategies, it applies a differential rather than a conventional integral approach to regulate the current vector. The outcomes suggest that an interior 
PMSM setup gives the strategy's dynamic performance and robustness.

The analysis of dual inverter driven PMSM is found in Lee et al. [5] and introduced a control mechanism to generate maximum power. The outcome of [5] this PMSM are accomplished to verify the feasibility.

The problem of neural networks (NNs) presented in Yu et al. [6] and presented adaptive dynamic surface control (DSC) for PMSMs with load torque disturbance, and it gives effectiveness and potential of the new design technique.

A model of PMSM with electromagnetically originated torque ripple given in Gebregergis et al. [7] where the author is aimed to develop an appropriate mitigation scheme for low torque ripple applications requiring four quadrant operations. For modelling analysis Finite-element (FE) analysis mechanism is used which verifies the lumped circuit model.

A position offset based multi-parameter estimation for PMSMs under variable speed control is introduced in Liu and Zhu [8] which does not require nominal parameter values of PMSM to estimate the rotor flux linkage and winding resistance separately. The outcomes suggested that the proposed system of [8] gives a better estimation of rotor flux linkage and winding resistance of permanent magnet. Towards controlling speed and current of PMSM Xia et al. [9] presented a proportional integral resonant (PIR) mechanism that minimizes the periodic torque ripples. The experimentation is performed at $10 \mathrm{~kW}$ setup in which it is observed that [9] yields minimized speed ripples.

The efficiency of electric drives can be enhanced by introducing optimal design. Hence, $\mathrm{Ni}$ et al. [10] given vector control mechanism which brings the maximum efficiency of PMSM during operation. The outcomes of [10] are compared with various control mechanisms with numerical data which suggests that [10] method is effective.

The mechanism of direct torque control (DTC) is given in Hoang et al. [11] where switching-table is used for dual 3phasePMSM. The optimized control mechanism that reduces stator harmonic currents. The outcomes of [11] significantly reduce the current harmonics. A particle swarm optimization (PSO) mechanism implementation is found in Sandre-Hernandez et al. [12]. The results of [12] indicate that PSO effective against current decay test. The study aiming towards fault tolerant control mechanism is observed in Wang et al. [13] during occurrence of faults in paralleled inverters fed PMSM. The outcomes of [13] were compared with other existing approaches to fault tolerance. A design of recurrent fuzzy neural networkbased control mechanisms is found in Lin et al. [14] were servo drive systems position is used to find different periodical position references offering robustness. This [14] system was implemented over 32-bit floating-point based digital signal processing for its performance analysis. An investigational work towards PMSM is found in Deng, and Nian [15] were MATLAB based simulation was utilizes to analyze the correctness of PMSM control strategies. The operational analysis of electromagnetic force (EMF) in high-speed operation of PMSM with the negligible iron loss this loss is minimized by adapting finite element analysis (FEA) and a look-up table. The outcomes of [15] were analyzed in a high-speed region. The work towards controlling the speed of PMSM with the sensorless control system is found in Kim et al. [16] where better speed control is achieved at a high-speed range. A predictive control mechanism by using Finite control set system is found in Formentini et al. [17] for PMSM. This mechanism replaces the traditional cascaded control mechanism with a single control law which controls speed and current of the motor. A mechanism for current control in PMSM is found in Carpiucet al. [18] which deals the problems associated with physical and real-time constraints. The system [18] adjusts stator voltages to achieve a speedy transient response of current, and the outcomes were analyzed with industrial hardware-in-the-loop test-bench.

A comparative evolutionary analysis is performed in Niu et al. [19] were DTC mechanisms of PMSM like basic DTC, model predictive DTC and DTC having duty ratio modulation. This [19] helps in selecting the control against application perspective.

The work of Kim et al. [20] gives an adaptive speed tracking control mechanism for a surface-mounted PMSM without an understanding of PMSM parameters. The outcomes of [20] represent the effectiveness of PMSM without its knowledge. In order to improve PMSM performance, a sensorless based control mechanism with a sliding-mode observer is found in Song et al. [21]. Through this, signal harmonics were significantly eliminated that brings feasibility in the system. The work of Wang et al. [22] gives the significant circulating mechanism for current control in PMSM. The system analysis is performed at a zero-sequence condition where circulating current is significantly reduced, and the theoretical analysis is performed at PMSM load condition.

A signal injection method is introduced in Xie et al. [23] were sensorless control mechanism is adapted at low speed. The system of [23] is easy to implement with least computational complexity. The implementation of three control schemes having dynamic switching frequencies is given in Wang et al. [24] where performance is analyzed by using paralleled voltagesource inverters (VSIs) with PMSM. The outcomes of [24] were analyzed with a laboratory prototype to validate the performance at variable switching frequencies. The work addressing predictive DTC is found in Vefaie et al. [25] which aims to bring the improvement in the variable response of traditional DTC and minimize the torque- and flux-ripples via a voltage vector with optimal phase. The comparison of [25] is performed with existing DTC mechanism and is observed that [25] come up with lower ripples at steady state and transient state responses.

An investigational study of Lin et al. [26] discusses the impact of machine saliency over sensorless control process. The outcomes of [26] bring improvement in the estimation of rotor position accuracy than another position observer. The performance [26] brings significant improvement at a steady and dynamic state condition.

The work of Cheema et al. [27] aimed for minimizing the ripple in the flux and the force, a duty ratio control mechanism for direct thrust force control of linear permanent magnet synchronous motors is proposed. The approach of [27] retains the characteristics of the conventional direct thrust control in terms of fast transient and steady-state responses for both flux and thrust force. The outcomes of the suggest a speedy transient response and a slight steady-state error for flux, force and speed responses by considering different operation condition and compared with existing approaches.

The investigational study of $\mathrm{Ni}$ et al. [28] describes the stators with both $\mathrm{Y}$ and delta connected windings attained the IE4 efficiency over remanufactured motors. An ampere algorithm is used at drive side of PMSM which helps to achieve maximum and is realized through position sensorless control mechanism that yields motor efficiency and minimizes the system cost. The system for application perspective the original induction motor is utilized at grid drive. In these seven different types of 
prototypes were used with rated powers and velocities were remanufactured.

The work of Mwasilu and Jung et al. [29] gives an enhanced sensor fault tolerant control (FTC) mechanism of an internal PMSM drive for the electric vehicle (EV) traction applications. Simulation is performed over MATLAB/Simulink, and experimentation over interior PMSM for feasibility analysis against Adaptive Extended Kalman (AEK)Filter and FRC more precisely estimates the rotor position with features robust to the position sensor failures than the conventional EKF.

Ge et al. [30] have presented a comprehensive and practical method of implementing speed range extended maximum torque per ampere control (MTPAC) for PMSM. Through this approach current transition, torque control accuracy, and efficiency performance is achieved entire torque-speed range. The investigational study of Feng et al. [31] gives the torque ripple minimization for PMSM and introduces a closed-loop controller using fuzzy logic. The current proposed controller is evaluated on a laboratory PMSM drive system under different load conditions and operating speeds. Chaoui et al. [32] presented an adaptive type-2 FLC for high-performance PMSM drives. To reduce the steady-state torque ripples for PMSM drives with predictive torque control (PTC), Zhou et al. [33] have introduced a modified PTC algorithm based on the extended control set (ECS-PTC). The outcomes suggest that ECS-PTC has excellent dynamic torque performance, and it also has more stable torque control performance and better execution efficiency at the same time.

Alvarez-Gonzalez et al. [34] give a high-fidelity implementation of the emulator in a hardware platform A research survey on DTC algorithms is presented in Wang et al. [35], were performance factors subjected to PMSM are discussed. Siami et al. [36] presented a predictive control for the control of matrix converters. The predictive control in PMSM can be divided as current predictive control (PCC) and torque control (PTC). The comparison involves the investigation of the torque and stator flux ripples, the total harmonic distortion (THD) of input and output currents and the input filter resonance as figures of merit.

The work of Khalil et al. [37] gives the research overview on essentials of control techniques for speed control of a PMSM. Furtherto minimizes the undesired torque, and flux ripples, Abosh and Zhu [38] gives a novel cascaded DTC mechanism for 3-phase PMSMs with asymmetric phase impedances. The analysis of the outcomes suggests the feasibility of the control mechanism under steady and dynamic state conditions.
To solve the problems associated with the predictive control algorithm, Zhou et al. [39] presented an improved predictiveintegral resonant control (PIRC) mechanism. The outcomes of this model give suppression of periodic disturbances in the drive system and enhance the performance related to current and speed. An optimum algorithm for PMSM is proposed in Cai et al. [40] and is tested in current-controlled $3-\mathrm{kW}$ surfacemounted PMSM drive at the different scenario. Direct control mechanism for PMSM is found in Smidi et al. [41], and it uses quadratic programming under quadratic constraint. The outcomes of this model are tested at 10.7-kW PMSM library prototype and come up with significant outcomes. To minimize the speed ripples in PMSM, the work of Houari et al. [42] presented an effective mechanism which treats the periodic torque ripples issues. The outcomes of this were analyzed through both simulation and experimental analysis.

The work of Repecho et al. [43] discussed issues of the PI-based control system and aimed to achieve faster transient response through DTC mechanism. The results of this model give the best speed control and faster transient response. Considering the tracking accuracy of speed and current, Jiang et al. [44] presented a deadbeat-based PCC mechanism. Using both SMC and deadbeat-based PCC the author is able to achieve robustness in current and speed tracking. The work of Liu and Fadel [45] gives Mono-Inverter Dual-PMSM system to share the static converters in electro-mechanical connected in parallel. This model provides both feasibility and performance improvement. The simulation and experimental analysis of Cunha et al. [46] gives voltage vector control for a PMSM driving a high-power subsea pump. The performance of DTC mechanism with optimal dynamic performance enhancement is given in Wang et al. [47] and the outcomes suggest the faster transient responses were achieved.

The nonlinear control mechanism was introduced in Thounthong et al. [48] to control both speed and torque of a PMSM drive. The validation is performed under dSPACE controller DS1l04 platform. The analysis of fault tolerant control mechanism for PMSM is found in Lin et al. [49], and the design is tested with the auxiliary model design which suggests steady operation and the fault-tolerant ability. A quadruple winding configuration for 3-phase PMSM is presented in Dieterle et al. [50] that gives improves control against current and speed.

Table.1: Summary of above-stated researches

\begin{tabular}{|c|c|c|c|c|}
\hline Authors & Problem-Focused & Technique Adapted/Presented & Outcome & Limitation \\
\hline Choi et al. [1] & $\begin{array}{l}\text { Design problems of } \\
\text { fuzzy PID } \\
\text { control }\end{array}$ & $\begin{array}{l}\text { An evolutionary algorithm } \\
\text { based Fuzzy PID controller }\end{array}$ & $\begin{array}{l}\text { Implemented in Texas } \\
\text { instruments }\end{array}$ & Not Benchmarked \\
\hline Jung et al. [2] & $\begin{array}{c}\text { Speed tracking in } \\
\text { PMSM }\end{array}$ & Adaptive PID control system & Faster transient response & Not Benchmarked \\
\hline Lee et al. [3]. & Flux weakening & $\begin{array}{c}\text { Seamless transition control } \\
\text { based on dual mode operation }\end{array}$ & Increased efficiency & Not Benchmarked \\
\hline Lemmens et al. [4] & $\begin{array}{c}\text { Constraint } \\
\text { optimization problem } \\
\text { in PMSM control }\end{array}$ & $\begin{array}{l}\text { Algorithm for PMSM optimal } \\
\text { current and voltage control }\end{array}$ & $\begin{array}{l}\text { Minimized error and } \\
\text { maximum efficiency }\end{array}$ & Not benchmarked \\
\hline Lee et al. [5] & $\begin{array}{l}\text { Speed control at an } \\
\text { entire range of speed }\end{array}$ & $\begin{array}{l}\text { Hybrid modulation mechanism } \\
\text { for open-end PMSM }\end{array}$ & $\begin{array}{l}\text { Maximized output and speed } \\
\text { control }\end{array}$ & Not benchmarked \\
\hline Yu et al. [6] & $\begin{array}{l}\text { Neural network based } \\
\text { control issues }\end{array}$ & $\begin{array}{l}\text { Adaptive dynamic surface } \\
\text { control system using a neural } \\
\text { network }\end{array}$ & Better error convergence & $\begin{array}{l}\text { Fuzzy logic is not } \\
\text { considered }\end{array}$ \\
\hline Gebregergis et al. [7] & $\begin{array}{l}\text { Understanding of } \\
\text { torque ripples }\end{array}$ & Modified d-q model & Better torque analysis & $\begin{array}{c}\text { Saturation effects were } \\
\text { neglected }\end{array}$ \\
\hline
\end{tabular}




\begin{tabular}{|c|c|c|c|c|}
\hline Liu and Zhu [8] & $\begin{array}{l}\text { Estimation of rotor } \\
\text { flux leakage }\end{array}$ & $\begin{array}{l}\text { Parameter estimation based on a } \\
\text { position offset }\end{array}$ & $\begin{array}{l}\text { A better performance against } \\
\text { variable speed }\end{array}$ & Not benchmarked \\
\hline Xia et al. [9] & $\begin{array}{l}\text { Issues of periodic } \\
\text { speed ripples }\end{array}$ & $\begin{array}{l}\text { Proportional integral resonant } \\
\text { Control (PIRC) mechanism }\end{array}$ & Minimized periodic ripples & Not benchmarked \\
\hline Ni et al. [10] & Efficiency of PMSM & $\begin{array}{l}\text { Maximum efficiency per ampere } \\
\text { control mechanism }\end{array}$ & Enhanced efficiency & $\begin{array}{l}\text { Speed control is not } \\
\text { considered }\end{array}$ \\
\hline Hoang et al. [11] & $\begin{array}{l}\text { Losses and efficiency } \\
\text { issues of PMSM }\end{array}$ & $\begin{array}{c}\text { Optimized switching table } \\
\text { mechanism }\end{array}$ & $\begin{array}{l}\text { Reduced harmonics and } \\
\text { achieves performance } \\
\text { enhancement }\end{array}$ & Not benchmarked \\
\hline Sandre-Hernandez et al. [12] & $\begin{array}{c}\text { Parameter } \\
\text { identification }\end{array}$ & $\begin{array}{l}\text { Particle Swarm optimization } \\
\text { based experimental analysis }\end{array}$ & $\begin{array}{l}\text { Low-cost parameter } \\
\text { identification }\end{array}$ & $\begin{array}{l}\text { Fuzzy logic is not } \\
\text { considered }\end{array}$ \\
\hline Wang et al. [13] & Fault tolerance & $\begin{array}{c}\text { Inverter-fed fault tolerance } \\
\text { control system }\end{array}$ & Fault-tolerant system & Not benchmarked \\
\hline Lin et al. [14] & $\begin{array}{c}\text { Tracking of the } \\
\text { position of servo drive }\end{array}$ & $\begin{array}{l}\text { The recurrent Fuzzy neural } \\
\text { control system }\end{array}$ & $\begin{array}{l}\text { Better position tracking of } \\
\text { servo drive }\end{array}$ & Not benchmarked \\
\hline Deng and Nian [15] & Load uncertainty & Robust control system & $\begin{array}{l}\text { Can deal uncertainty and } \\
\text { offers efficient current and } \\
\text { speed performance }\end{array}$ & $\begin{array}{l}\text { Not benchmarked with } \\
\text { the existing system }\end{array}$ \\
\hline Kim et al. [16] & Speed control & Sensorless speed control & $\begin{array}{l}\text { Overcomes angle difference } \\
\text { in the High-speed range }\end{array}$ & $\begin{array}{l}\text { Not considered fault } \\
\text { tolerance }\end{array}$ \\
\hline Formentini et al. [17] & Speed control & Predictive control system & Better flux and speed control & $\begin{array}{c}\text { Not considered fault } \\
\text { tolerance }\end{array}$ \\
\hline Carpiuc et al. [18] & $\begin{array}{c}\text { Issues of current } \\
\text { control }\end{array}$ & $\begin{array}{l}\text { The real-time predictive control } \\
\text { system }\end{array}$ & $\begin{array}{l}\text { Reduced speed control and } \\
\text { complexity }\end{array}$ & Not benchmarked \\
\hline Niu et al. [19] & $\begin{array}{l}\text { Torque and stator flux } \\
\text { ripples }\end{array}$ & Comparative analysis & Reduced switching frequency & $\begin{array}{l}\text { Not benchmarked with } \\
\text { speed performed }\end{array}$ \\
\hline Kim et al. [20] & Parameter estimation & $\begin{array}{l}\text { Adaptive speed tracking } \\
\text { technique }\end{array}$ & $\begin{array}{l}\text { Enhanced performance at load } \\
\text { and speed control }\end{array}$ & Not benchmarked \\
\hline Song et al. [21] & $\begin{array}{l}\text { Rotor position } \\
\text { estimation }\end{array}$ & $\begin{array}{l}\text { Adaptive compensation } \\
\text { mechanism with position } \\
\text { estimation error }\end{array}$ & $\begin{array}{l}\text { Harmonics filter and speed } \\
\text { control for high-speed } \\
\text { applications }\end{array}$ & Not benchmarked \\
\hline Wang et al. [22] & $\begin{array}{l}\text { Suppression of } \\
\text { circulating current }\end{array}$ & $\begin{array}{l}\text { Circulating current control } \\
\text { mechanism }\end{array}$ & $\begin{array}{l}\text { Suppresses current in both } \\
\text { steady and transient state }\end{array}$ & $\begin{array}{l}\text { Not considered speed } \\
\text { and fault condition of } \\
\text { PMSM }\end{array}$ \\
\hline Xie et al. [23] & $\begin{array}{l}\text { Speed variation and } \\
\text { position estimation }\end{array}$ & $\begin{array}{c}\text { Sensorless minimum voltage } \\
\text { vector mechanism }\end{array}$ & $\begin{array}{c}\text { Better speed and position } \\
\text { estimation }\end{array}$ & $\begin{array}{l}\text { Fault tolerance is not } \\
\text { considered }\end{array}$ \\
\hline Wang et al. [24] & Torque control & DTC & Better torque control & $\begin{array}{c}\text { Not considered speed } \\
\text { control }\end{array}$ \\
\hline Vefaie et al. [25] & Torque control & Predictive-based torque control & $\begin{array}{c}\text { Low ripples and faster } \\
\text { response } \\
\end{array}$ & $\begin{array}{c}\text { Not considered speed } \\
\text { control }\end{array}$ \\
\hline Lin et al. [26] & $\begin{array}{l}\text { Rotor position } \\
\text { estimation }\end{array}$ & $\begin{array}{l}\text { The modified sensorless control } \\
\text { system }\end{array}$ & $\begin{array}{l}\text { Enhanced position estimation } \\
\text { of rotor }\end{array}$ & $\begin{array}{l}\text { Nor considered steady } \\
\text { state and faulty } \\
\text { condition }\end{array}$ \\
\hline Cheema et al. [27] & Flux ripples & Direct thrust control mechanism & $\begin{array}{l}\text { Reduced flux ripples, speed } \\
\text { response }\end{array}$ & Not benchmarked \\
\hline Ni et al. [28] & $\begin{array}{l}\text { Efficiency } \\
\text { enhancement in } \\
\text { PMSM }\end{array}$ & $\begin{array}{l}\text { Remanufacturing of the } \\
\text { induction motor }\end{array}$ & $\begin{array}{l}\text { Enhanced efficiency and } \\
\text { reduced system cost }\end{array}$ & Not benchmarked \\
\hline Mwasilu and Jung et al. [29] & $\begin{array}{l}\text { Fault tolerance, rotor } \\
\text { position }\end{array}$ & Enhanced fault tolerant system & $\begin{array}{l}\text { Robustness against position } \\
\text { sensor failures, better } \\
\text { estimation of rotor position }\end{array}$ & Not benchmarked \\
\hline Ge et al. [30] & $\begin{array}{l}\text { Speed control and } \\
\text { torque maximization }\end{array}$ & $\begin{array}{l}\text { Maximum torque per ampere } \\
\text { control }\end{array}$ & $\begin{array}{c}\text { Enhanced torque control } \\
\text { accuracy and efficiency } \\
\text { enhancement }\end{array}$ & Not benchmarked \\
\hline Feng et al. [31] & Torque ripples & $\begin{array}{l}\text { Closed loop based Fuzzy logic } \\
\text { controller }\end{array}$ & $\begin{array}{l}\text { Minimized torque ripples at } \\
\text { the different load condition }\end{array}$ & $\begin{array}{l}\text { Not benchmarked, not } \\
\text { implemented in real- } \\
\text { time applications }\end{array}$ \\
\hline Chaoui et al. [32] & $\begin{array}{l}\text { Rotor position } \\
\text { tracking }\end{array}$ & $\begin{array}{l}\text { Adaptive Fuzzy logic type } 2 \\
\text { controller }\end{array}$ & $\begin{array}{c}\text { Accurate rotor position } \\
\text { tracking }\end{array}$ & Not benchmarked \\
\hline Zhou et al. [33] & Torque ripples & Predictive torque control & $\begin{array}{c}\text { Reduced torque ripples and } \\
\text { enhanced computational } \\
\text { efficiency }\end{array}$ & $\begin{array}{l}\text { Not benchmarked and } \\
\text { speed parameter is not } \\
\text { considered }\end{array}$ \\
\hline Lvarez-Gonzalez et al. [34] & $\begin{array}{c}\text { Nonlinearities like } \\
\text { saturation, harmonics }\end{array}$ & $\begin{array}{l}\text { Real-time hardware-based } \\
\text { simulation }\end{array}$ & $\begin{array}{l}\text { Computational efficiency is } \\
\text { enhanced }\end{array}$ & $\begin{array}{c}\text { Not a Fuzzy logic based } \\
\text { approach }\end{array}$ \\
\hline Wang et al. [35] & PMSM control issues & Survey & Overview of direct control & Not an implementation \\
\hline
\end{tabular}




\begin{tabular}{|c|c|c|c|c|}
\hline & & & algorithms & work \\
\hline Siami et al. [36] & $\begin{array}{l}\text { Current and Torque } \\
\text { control }\end{array}$ & $\begin{array}{l}\text { Predictive current and torque } \\
\text { control mechanisms }\end{array}$ & $\begin{array}{l}\text { Achieved reduced flux ripples } \\
\text { and harmonics }\end{array}$ & Not benchmarked \\
\hline Khalil et al. [37] & $\begin{array}{l}\text { The high gain speed } \\
\text { controller }\end{array}$ & Survey & $\begin{array}{l}\text { Theoretical background of } \\
\text { feedback control for PMSM }\end{array}$ & $\begin{array}{l}\text { Not an implementation } \\
\text { work }\end{array}$ \\
\hline Abosh and Zhu [38] & $\begin{array}{c}\text { Undesired torque and } \\
\text { flux ripples } \\
\end{array}$ & Cascaded DTC & $\begin{array}{l}\text { Reduced flux and torque } \\
\text { ripples }\end{array}$ & $\begin{array}{l}\text { Not benchmarked and } \\
\text { speed is not considered }\end{array}$ \\
\hline Zhou et al. [39] & $\begin{array}{c}\text { Undesired torque } \\
\text { ripples and speed } \\
\text { control }\end{array}$ & $\begin{array}{l}\text { Predictive-based integral } \\
\text { resonant controller }\end{array}$ & $\begin{array}{l}\text { Reduced flux and better speed } \\
\text { control }\end{array}$ & Not benchmarked \\
\hline Cai et al. [40] & State transition & $\begin{array}{c}\text { Comparative analysis of } \\
\text { Optimum and discrete solutions }\end{array}$ & Better current control & $\begin{array}{l}\text { Not benchmarked with } \\
\text { fault tolerance and speed } \\
\text { control }\end{array}$ \\
\hline Smidi et al. [41] & Speed control & Direct speed control mechanism & Better current control & $\begin{array}{c}\text { Not benchmarked with } \\
\text { fault tolerance and speed } \\
\text { control }\end{array}$ \\
\hline Houari et al. [42] & $\begin{array}{l}\text { Low-speed operation } \\
\text { of PMSM }\end{array}$ & Compensation technique & $\begin{array}{c}\text { Reduced speed ripples at low- } \\
\text { speed operation }\end{array}$ & Not benchmarked \\
\hline Repecho et al. [43] & Speed, torque control & $\begin{array}{l}\text { The sliding model control } \\
\text { system }\end{array}$ & $\begin{array}{c}\text { Better speed control and } \\
\text { torque control }\end{array}$ & Not benchmarked \\
\hline Jiang et al. [44] & $\begin{array}{l}\text { Speed and current } \\
\text { control }\end{array}$ & $\begin{array}{l}\text { Sliding mode based Control } \\
\text { system }\end{array}$ & $\begin{array}{l}\text { Better speed and current } \\
\text { control }\end{array}$ & Not benchmarked \\
\hline Liu and Fadel [45] & $\begin{array}{l}\text { Performance } \\
\text { enhancement }\end{array}$ & $\begin{array}{l}\text { The efficient optimal control } \\
\text { system }\end{array}$ & $\begin{array}{c}\text { Feasible and enhanced } \\
\text { performance }\end{array}$ & Not benchmarked \\
\hline Cunha et al. [46] & Transient response & Sensorless vector control system & Fast transient response & Not benchmarked \\
\hline Wang et al. [47] & $\begin{array}{l}\text { Dynamic performance } \\
\text { and speed control }\end{array}$ & Optimal control system & $\begin{array}{c}\text { Better dynamic response and } \\
\text { speed control }\end{array}$ & $\begin{array}{c}\text { Not benchmarked with } \\
\text { fault tolerance }\end{array}$ \\
\hline Thounthong et al. [48] & $\begin{array}{c}\text { Speed and torque } \\
\text { control }\end{array}$ & $\begin{array}{c}\text { Differential speed and torque } \\
\text { control }\end{array}$ & $\begin{array}{c}\text { Better speed and torque } \\
\text { control }\end{array}$ & Not benchmarked \\
\hline Lin et al. [49] & $\begin{array}{l}\text { Speed and torque } \\
\text { control }\end{array}$ & Auxiliary modular design & $\begin{array}{l}\text { Better torque control ability } \\
\text { and speed control }\end{array}$ & Not benchmarked \\
\hline Dieterle et al. [50] & $\begin{array}{c}\text { Winding } \\
\text { configuration and } \\
\text { fault tolerance }\end{array}$ & $\begin{array}{l}\text { The quadruple 3-phase control } \\
\text { system }\end{array}$ & Better performance & Not benchmarked \\
\hline
\end{tabular}

\section{RESEARCH GAP}

The recent researches have suggested that the PMSM is widely used for high torque per current ratio and performance applications like in robots and industrial machines and are able to handle with accuracy and high-performance factors and also with flexibility and efficiency in the design and implementation process. The traditional PI and PID controllers were mainly considered to control the speed of PMSM drives. However, the practical consideration with PMSM nonlinear system is not much considered as it generates large disturbances, uncertainties, and parameters variations. Thus, the desired control mechanism is required to get better adjustment performances in various working conditions. Hence, it is very difficult to differentiate system characteristics and dynamic control parameters in real time due to the complexity of the PMSM servo system. Thus various, nonlinear control mechanism of PMSM was presented to enhance system control performances under different disturbances and uncertainties. Different nonlinear control mechanism was developed for PMSM system which includes adaptive control, robust control, sliding mode control, input-output linearization control, backstepping control, neural network control, fuzzy control, and finite-time control, predictive control, intelligent control, etc. These methods were designed to improve PMSM performance at different load condition and various speeds.

On analyzing all the above-selected researches, it is been found that the work towards addressing control issues of PMSM are very much concentrated on the single parameter for performance enhancement of PMSM. Some of the points which are observed after review analysis is that:
- Lack of researches towards intelligence approaches: There are a greater number of researches were presented in recent past and are mainly focused on enhancing the performance with traditional or other non-intelligence methods which are mainly found in Choi et al. [1], Jung et al. [2], Lee et al. [3], Lemmens et al. [4], Lee et al. [5], Yu et al. [6], Gebregergis et al. [7], Liu and Zhu [8] etc.

- $\quad$ Rare Fuzzy logic implementation: From recent works analysis it is been found that Yu et al. [6] and SandreHernandez et al. [12] are the only presented in recent years. (from IEEE Xplore: 2015-2018).

- Rare works are addressing both speed and fault tolerance: Though there have been many efforts towards, understanding the operating conditions, fault causes, mechanism of the possible fault tolerance, but yet the robust and efficient design by means of optimization and use of machine learning approach with fuzzy logic need to be achieved.

- Less benchmarked works: From the review, almost all the works were not benchmarked with existing works and hence need to have better comparative analysis

\section{STATISTICAL ANALYSIS OF THE RESEARCHES IN PMSM CONTROL}

The statistical analysis of the research works presented towards PMSM control is performed by performing a search of the total number of published papers in IEEE and Springer. The search is 
performed by providing the keyword "PMSM Control," and it cited at 06:15 pm (IST) on 09-November-2018. The numerical data found is represented in Table. 2 and 3 from IEEE Xplore and Springer.

Table.2: Numerical data found from IEEE

\begin{tabular}{|l|l|}
\hline Type of Publications & Counts \\
\hline Conferences & 4191 \\
\hline Journals and Magazines & 745 \\
\hline Early Access Articles & 39 \\
\hline Books & 1 \\
\hline Courses & 1 \\
\hline
\end{tabular}

Table.3: Numerical data found from Springer

\begin{tabular}{|l|l|}
\hline Type of Publications & Counts \\
\hline Books & 25,796 \\
\hline Journals & 383 \\
\hline Series & 151 \\
\hline Web pages & 43 \\
\hline
\end{tabular}

The graphical representation of these numerical data is given in Figure.5. From the Figure.5, it is observed that number of books were published in Springer than IEEE while number of journals were presented in IEEE than Springer. Also, it is found that early access articles, courses, and conferences were not published in Springer. On the other hand, the IEEE digital library is missing with web pages and series.

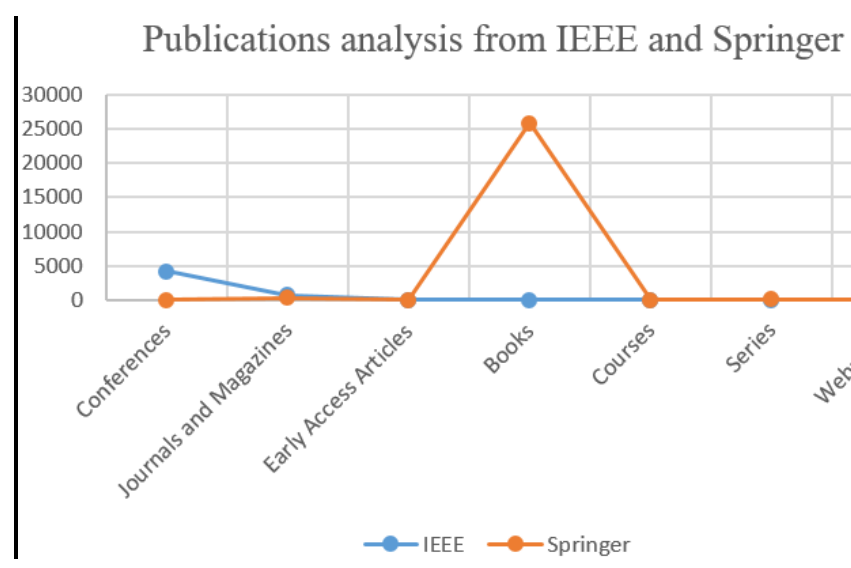

Fig.5: Publication analysis from IEEE and Springer

\section{CONCLUSION}

This paper states conceptual points of PMSM along with current state of the art in PMSM control research domain. From the research analysis of existing control research lot of works have considered speed and fault tolerance issues separately. However, very rare works were incorporated with both issues. Though there have been many efforts towards, understanding the operating conditions, fault causes, mechanism of the possible fault tolerance, but yet the robust and efficient design by means of optimization and use of machine learning approach with fuzzy logic need to be achieved.

Further, this research survey can be considered for developing a fault tolerant system for PMSM under healthy and unhealthy conditions by adapting fuzzy logic control.

\section{REFERENCES}

[1] Choi, Han Ho, Hong Min Yun, and Yong Kim. "Implementation of evolutionary fuzzy PID speed controller for PM synchronous motor." IEEE Transactions on Industrial Informatics 11.2 (2015): 540-547.
[2] Jung, Jin-Woo, et al. "Adaptive PID speed control design for permanent magnet synchronous motor drives." IEEE Transactions on Power Electronics 30.2 (2015): 900-908.

[3] Lee, Kwang-Woon, Sungin Park, and Seongki Jeong. "A seamless transition control of sensorless PMSM compressor drives for improving efficiency based on a dual-mode operation." IEEE Transactions on Power Electronics 30.3 (2015): 1446-1456.

[4] Lemmens, Joris, Piet Vanassche, and Johan Driesen. "PMSM drive current and voltage limiting as a constraint optimal control problem." IEEE Journal of emerging and selected topics in power electronics 3.2 (2015): 326-338.

[5] Lee, Yongjae, and Jung-Ik Ha. "Hybrid modulation of the dual inverter for open-end permanent magnet synchronous motor." IEEE Trans. Power Electron 30.6 (2015): 32863299.

[6] Yu, Jinpeng, et al. "Neural network-based adaptive dynamic surface control for permanent magnet synchronous motors." IEEE Trans. Neural Netw. Learning Syst. 26.3 (2015): 640-645.

[7] Gebregergis, Abraham, et al. "Modeling of permanentmagnet synchronous machine including torque ripple effects." IEEE Transactions on Industry Applications 51.1 (2015): 232-239.

[8] Liu, Kan, and Zi-Qiang Zhu. "Position offset-based

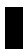
parameter estimation for permanent magnet synchronous nachines under variable speed control." IEEE Transactions on Power Electronics 30.6 (2015): 3438-3446.

Kia, Changliang, Bingnan Ji, and Yan Yan. "Smooth Speed fontrol for Low-Speed High-Torque Permanent-Magnet synchronous Motor Using Proportional-Integral-Resonant Controller." IEEE Trans. Industrial Electronics 62.4 (2015): 123-2134.

$\mathrm{Ni}$, Ronggang, et al. "Maximum efficiency per ampere ontrol of permanent-magnet synchronous machines." IEEE Transactions on Industrial Electronics 62.4 (2015): 2135143.

Hoang, Khoa Dang, et al. "Modified switching-table trategy for reduction of current harmonics in direct torque controlled dual-three-phase permanent magnet synchronous machine drives." IET Electric Power Applications 9.1 (2014): 10-19.

[12] Sandre-Hernandez, Omar, et al. "Parameter identification of PMSMs using experimental measurements and a PSO algorithm." IEEE Transactions on Instrumentation and Measurement 64.8 (2015): 2146-2154.

[13] Wang, Zheng, et al. "Fault-tolerant control of paralleledvoltage-source-inverter-fed PMSM drives." IEEE Transactions on Industrial Electronics 62.8 (2015): 47494760.

[14] Lin, Faa-Jeng, et al. "Intelligent position control of permanent magnet synchronous motor using recurrent fuzzy neural cerebellar model articulation network." IET Electric Power Applications 9.3 (2015): 248-264.

[15] Su, Yu Xin, Chun Hong Zheng, and Bao Yan Duan. "Automatic disturbances rejection controller for precise motion control of permanent-magnet synchronous motors." IEEE Transactions on Industrial Electronics 52.3 (2005): 814-823. 
[16] Kim, Junwoo, et al. "Sensorless control of PMSM in a high-speed region considering iron loss." IEEE Transactions on Industrial Electronics 62.10 (2015): 61516159 .

[17] Formentini, Andrea, et al. "Speed finite control set model predictive control of a PMSM fed by matrix converter." IEEE Transactions on Industrial Electronics 62.11 (2015): 6786-6796.

[18] Carpiuc, Sabin-Constantin, and Corneliu Lazar. "Fast realtime constrained predictive current control in permanent magnet synchronous machine-based automotive traction drives." IEEE Transactions on Transportation Electrification 1.4 (2015): 326-335.

[19] Niu, Feng, et al. "Comparative evaluation of direct torque control strategies for permanent magnet synchronous machines." IEEE Transactions on Power Electronics 31.2 (2016): 1408-1424.

[20] Kim, Seok-Kyoon, Kyoung-Gu Lee, and Kyo-Beum Lee. "Singularity-free adaptive speed tracking control for uncertain permanent magnet synchronous motor." IEEE Transactions on Power Electronics 31.2 (2016): 1692-1701.

[21] Song, Xinda, et al. "Adaptive compensation method for high-speed surface PMSM sensorless drives of EMF-based position estimation error." IEEE Transactions on Power Electronics 31.2 (2016): 1438-1449.

[22] Wang, Fei, et al. "A control strategy for suppressing circulating currents in parallel-connected PMSM drives with individual DC links." IEEE Transactions on Power Electronics 31.2 (2016): 1680-1691.

[23] Xie, Ge, et al. "Minimum-voltage vector injection method for sensorless control of PMSM for low-speed operations." IEEE Transactions on Power Electronics 31.2 (2016): 1785-1794.

[24] Wang, Zheng, et al. "Field-oriented control and direct torque control for paralleled VSIs fed PMSM drives with variable switching frequencies." IEEE Transactions on Power Electronics 31.3 (2016): 2417-2428.

[25] Vafaie, Mohammad Hossein, et al. "A new predictive direct torque control method for improving both steady-state and transient-state operations of the PMSM." IEEE Transactions on power electronics 31.5 (2016): 3738-3753.

[26] Lin, Tzu-Chi, et al. "Improved sensorless control of switched-flux permanent-magnet synchronous machines based on different winding configurations." IEEE Transactions on Industrial Electronics 63.1 (2016): 123132.

[27] Cheema, Muhammad Ali Masood, et al. "A direct thrust control scheme for linear permanent magnet synchronous motor based on online duty ratio control." IEEE Transactions on Power Electronics 31.6 (2016): 4416-4428.

[28] Ni, Ronggang, et al. "Efficiency Enhancement of General AC Drive System by Remanufacturing Induction Motor With Interior Permanent-Magnet Rotor." IEEE Trans. Industrial Electronics 63.2 (2016): 808-820.

[29] Mwasilu, Francis, and Jin-Woo Jung. "Enhanced faulttolerant control of interior PMSMs based on an adaptive EKF for EV traction applications." IEEE Transactions on Power Electronics 31.8 (2016): 5746-5758.

[30] Ge, Hao, et al. "Speed range extended maximum torque per ampere control for PM drives considering inverter and motor nonlinearities." IEEE Transactions on Power Electronics 32.9 (2017): 7151-7159.

[31] Feng, Guodong, Chunyan Lai, and Narayan C. Kar. "A closed-loop fuzzy-logic-based current controller for PMSM torque ripple minimization using the magnitude of speed harmonic as the feedback control signal." IEEE Transactions on Industrial Electronics 64.4 (2017): 26422653.

[32] Chaoui, Hicham, Mehdy Khayamy, and Abdullah Abdulaziz Aljarboua. "Adaptive interval type-2 fuzzy logic control for PMSM drives with a modified reference frame." IEEE Transactions on Industrial Electronics 64.5 (2017): 3786-3797.

[33] Zhou, Zhanqing, et al. "Torque ripple minimization of predictive torque control for PMSM with extended control set." IEEE Transactions on Industrial Electronics 64.9 (2017): 6930-6939.

[34] Alvarez-Gonzalez, Fernando, et al. "Real-Time Hardwarein-the-Loop Simulation of Permanent-Magnet Synchronous Motor Drives Under Stator Faults." IEEE Transactions on Industrial Electronics 64.9 (2017): 6960-6969.

[35] Wang, Yi, J. G. Zhu, and Y. G. Guo. "A survey of direct torque control schemes for permanent magnet synchronous motor drives." Power Engineering Conference, 2007. AUPEC 2007. Australasian Universities. IEEE, 2007.

[36] Siami, Mohsen, et al. "An experimental evaluation of predictive current control and predictive torque control for a pmsm fed by a matrix converter." IEEE Trans. Ind. Electron 64.11 (2017): 8459-8471.

[37] Khalil, Hassan K. "High-gain observers in feedback control: Application to permanent magnet synchronous motors." IEEE Control Systems 37.3 (2017): 25-41.

[38] Abosh, Atheer H., Zi-Qiang Zhu, and Yuan Ren. "Cascaded Direct Torque Control of Unbalanced PMSM With Low Torque and Flux Ripples." IEEE Transactions on Power Electronics 33.2 (2018): 1740-1749.

[39] Zhou, Zhanqing, et al. "Disturbances attenuation of permanent magnet synchronous motor drives using cascaded predictive-integral-resonant controllers." IEEE Trans. Power Electron. 33.2 (2018): 1514-1527.

[40] Cai, Xinbo, et al. "Optimal Control Solutions for PMSM Drives: A Comparison Study With Experimental Assessments." IEEE Journal of Emerging and Selected Topics in Power Electronics 6.1 (2018): 352-362.

[41] Šmídl, Václav, et al. "Direct Speed Control of a PMSM Drive Using SDRE and Convex Constrained Optimization." IEEE Transactions on Industrial Electronics 65.1 (2018): $532-542$.

[42] Houari, Azeddine, et al. "An Effective Compensation Technique for Speed Smoothness at Low-Speed Operation of PMSM Drives." IEEE Transactions on Industry Applications 54.1 (2018): 647-655.

[43] Repecho, Víctor, Domingo Biel, and Antoni Arias. "Fixed switching period discrete-time sliding mode current control of a PMSM." IEEE Transactions on Industrial Electronics 65.3 (2018): 2039-2048.

[44] Jiang, Yajie, et al. "Improved Deadbeat Predictive Current Control Combined Sliding Mode Strategy for PMSM Drive 
System." IEEE Transactions on Vehicular Technology 67.1 (2018): 251-263

[45] Liu, Tianyi, and Maurice Fadel. "An Efficiency-Optimal Control Method for Mono-Inverter Dual-PMSM Systems." IEEE Transactions on Industry Applications 54.2 (2018): $1737-1745$.

[46] da Cunha, Gilberto, et al. "Control of permanent magnet synchronous machines for subsea applications." Petroleum and Chemical Industry Technical Conference (PCIC), 2017. IEEE, 2017.

[47] Wang, Yu, et al. "Control Method for Optimal Dynamic Performance of DTC based PMSM drives." IEEE Transactions on Energy Conversion (2018).
[48] Thounthong, Phatiphat, et al. "Nonlinear Differential Flatness-Based Speed/Torque Control With StateObservers of Permanent Magnet Synchronous Motor Drives." IEEE Transactions on Industry Applications 54.3 (2018): 2874-2884.

[49] Lin, Hai, Fei Zhao, and Byung-Il Kwon. "Analysis and Control of the Permanent Magnet Synchronous Motor With Auxiliary Modular Design." IEEE Transactions on Magnetics 99 (2018): 1-6.

[50] Dieterle, Oliver, Thomas Greiner, and Peter Heidrich. "Control of a PMSM With Quadruple Three-Phase StarConnected Windings Under Inverter Short-Circuit Fault." IEEE Transactions on Industrial Electronics 66.1 (2019): 685-695. 